\title{
Estudantes de curso técnico em enfermagem e sua motivação para o trabalho em enfermagem
}

Students in a nurse technician course and their motivation for working in the field

Estudiantes de curso técnico de enfermería y su motivación para el trabajo en enfermería

Maria José Sanches Marin ${ }^{1}$, Milenne Ura Seixas Santos Dias ${ }^{2}$, Silvia Franco da Rocha Tonhom ${ }^{3}$, Adriana Paula Congro Michelone ${ }^{4}$, Mário do Carmo Martini Bernardo 5

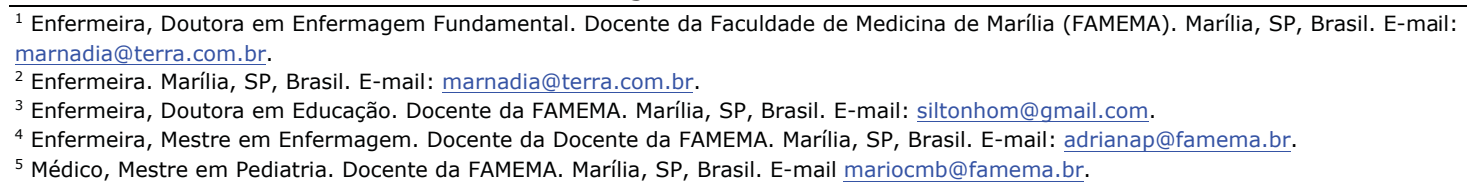

\section{RESUMO}

Este estudo se propôs a analisar as motivações de estudantes de um curso técnico em enfermagem para o trabalho em saúde. Estudo exploratório realizado com 18 estudantes de uma instituição de ensino de nível médio e a partir de um questionário com questão aberta sobre as motivações para o trabalho na área. Os dados foram analisados pela técnica de análise temática. Os entrevistados apontaram que a motivação para o trabalho se deve ao sentimento de realização e de responsabilidade profissional, bem como ao incentivo externo. Em contrapartida, indicaram quanto à falta de opção para atingir outros patamares e para o desgaste pessoal diante do sofrimento. Convivem, portanto, com o sofrimento e com o prazer. A partir desse reconhecimento, é importante que sejam adotadas medidas de incentivo ao desenvolvimento profissional e melhorias nas condições de trabalho.

Descritores: Formação de Recursos Humanos; Satisfação no Emprego; Educação Técnica em Enfermagem.

\section{ABSTRACT}

The present study aims at analyzing the motivations of students in a nurse technician course for working in the health field. It is an exploratory study conducted with 18 students at a high school institution, through an open-ended questionnaire about their motivations for working in the field. The data were analyzed using the thematic analysis technique. The interviewees indicate that their motivation for such work is due to the feeling of accomplishment and professional responsibility, as well as external incentives. On the other hand, they point to the lack of options for reaching higher professional levels and the personal fatigue of being exposed to suffering. Thus, they experience both suffering and pleasure. Based on these findings, it is important to adopt measures to incentivize their professional development and improve working conditions.

Descriptors: Staff Development; Job Satisfaction; Education, Nursing, Associate.

\section{RESUMEN}

Este estudio se propone analizar las motivaciones de estudiantes de un curso técnico de enfermería para el trabajo en salud. Estudio exploratorio, realizado con 18 estudiantes de una institución de enseñanza de nivel medio, a partir de un cuestionario con pregunta abierta sobre las motivaciones para el trabajo en el área. Los datos fueron analizados según la técnica del análisis temático. Los entrevistados refieren que la motivación para el trabajo se debe al sentimiento de realización y de responsabilidad profesional, así como al incentivo externo. En contrapartida, expresan la falta de opciones para alcanzar otros niveles y el desgaste personal ante el sufrimiento. Conviven, por lo tanto, con el sufrimiento y con el placer. A partir de dicho reconocimiento, es importante que se adopten medidas de incentivación para su desarrollo profesional y mejoras en las condiciones de trabajo.

Descriptores: Desarrollo de Personal; Satisfacción en el Trabajo; Graduación en Auxiliar de Enfermería. 


\section{INTRODUÇÃo}

A crescente evolução tecnológica mundial vem trazendo mudanças no mundo do trabalho devido à substituição do trabalho humano pela mecanização. Diferentemente dessa realidade, na área da saúde, existe uma inversão já que em suas características está incluso o contato humano que, frente ao crescente aumento populacional, especialmente o das pessoas idosas e dependentes, torna as relações insubstituíveis e cada vez mais necessárias.

Pela análise da força de trabalho em saúde, constata-se uma polarização entre médicos (12\%) e os profissionais de nível médio e elementar (57\%), num total de $69 \%$. Entre aqueles de nível médio e elementar, há predomínio de profissionais da área da Enfermagem $(64,6 \%)^{(1)}$.

Diante do significativo contingente de profissionais de nível médio no contexto do trabalho em saúde, com prevalência do auxiliar e do técnico de enfermagem, e, considerando que a principal característica da sua prática é a de preservar a vida e a saúde da pessoa, da família e da comunidade, fundamentado nos princípios humanos e éticos, tendo como essência a relação interpessoal, torna-se imprescindível maior investimento nessa categoria profissional a fim de melhor qualificar a atenção em saúde.

Do ponto de vista da legislação nacional, observamse alguns incentivos para essa formação. Exemplo disso ocorreu em 1981, com o Projeto de Formação de Trabalhadores para a Área de Saúde em Larga Escala, cujo objetivo era promover qualificação de pessoal de nível médio e elementar, já atuante nos serviços públicos de saúde, e que não havia tido oportunidade de profissionalização(2) ${ }^{(2 m}$ outubro de 1999, foi criado o Programa de Profissionalização dos Trabalhadores da Área da Enfermagem (PROFAE), um projeto do Ministério da Saúde, com a meta de profissionalização em grande escala dos trabalhadores da área da saúde de nível médio, especificamente os auxiliares e técnicos de enfermagem ${ }^{(3)}$.

Mais recentemente, por meio da Fundação do Desenvolvimento Administrativo (FUNDAP), órgão do Governo do Estado, realiza-se o Téc-Saúde - Programa de Formação de Profissionais de Nível Técnico para a Área de Saúde no Estado de São Paulo. Esse projeto, destinado aos profissionais atuantes na área da saúde, tem como objetivo ampliar o nível de formação dos trabalhadores por meio da formação de profissionais de nível técnico com habilitações para o ingresso no mercado de trabalho e melhorar a qualidade dos serviços de saúde prestados à população, no âmbito do Sistema Único de Saúde (SUS) no estado ${ }^{(4)}$.

A formação de profissionais para atuar em conformidade com os princípios e diretrizes do SUS pressupõe a inclusão de novas tecnologias e o desenvolvimento de competências que ultrapassam a simples capacidade de realização de procedimentos técnicos e do cuidado fragmentado e voltado para os aspectos biológicos, o que até então havia sido enfatizado na formação em saúde.

O técnico de enfermagem é um profissional que atua na área da promoção da saúde, na prevenção de agravos, na recuperação e na reabilitação da saúde, além de participar da gestão, prestando assistência às pessoas em todas as fases do ciclo vital, família e comunidade, no âmbito de suas competências, conforme a legislação de enfermagem que rege seu exercício profissional. Pode-se afirmar que se trata do profissional da equipe de saúde com grande proximidade com o cuidado direto, sendo, portanto, muitas vezes, o grande responsável pela realização do arranjo final de toda a organização estrutural e processual do sistema de saúde ${ }^{(5)}$.

O contato direto com seres humanos que apresentam necessidades de saúde eminentes coloca o profissional de saúde diante de sua própria vida, saúde ou doença, diante dos próprios conflitos e frustrações. Apesar disso, os profissionais que exercem tal função, na maioria das vezes, recebem remuneração incompatível com condições dignas de sobrevivência, sendo obrigados à dupla jornada de trabalho, fato agravante visto ser uma profissão exercida principalmente por mulheres que também acumulam as atividades do ambiente familiar.

A composição da força de trabalho da enfermagem em diferentes categorias faz com que haja reforço na divisão social do trabalho e na dicotomia entre fazer e pensar, produzindo diferentes status/reconhecimento, cabendo ao técnico, muitas vezes, o cumprimento de tarefas repetitivas ${ }^{(6)}$.

Acresce às suas atribuições a necessidade de atualização e de capacitação, com a finalidade de melhorar as condições de enfrentamento da competitividade existente no mercado de trabalho. Sobre a enfermagem profissionalizante no Brasil, descrevem-se importantes desafios, uma vez que nem todos os professores estão adequadamente preparados, a estrutura institucional é insuficiente e o ensino é fragmentado e focado no procedimento técnico ${ }^{(7)}$. Egressos de um curso de formação técnica para auxiliares de enfermagem, destacam que, embora 
tenham adquirido maior iniciativa e preparo teórico, o curso não produziu a mobilidade no mercado de trabalho como se esperava(8).

Frente aos distintos fatores que podem afetar a inserção de estudantes de enfermagem no trabalho em saúde, no papel de técnico de enfermagem cabem questionamentos sobre os aspectos que motivam tais profissionais para o exercício da profissão.

Dada a relevância do papel deste profissional na qualidade da atenção em saúde e percebendo as dificuldades pessoais e profissionais que enfrentam no seu cotidiano, principalmente aqueles que se propõem à qualificação profissional, reveste-se de relevância o reconhecimento da motivação para o trabalho entre estudantes de um curso técnico que já atuam na área da saúde.

Sendo assim, o estudo propõe-se a conhecer os aspectos motivacionais para o trabalho em saúde dos estudantes de um curso técnico de enfermagem.

\section{MÉTODO}

Trata-se de um estudo exploratório, de abordagem qualitativa, cuja coleta de dados ocorreu nas dependências de uma instituição de ensino que ministra cursos de Auxiliar e Técnico de Enfermagem, em uma cidade localizada na região noroeste do Estado de São Paulo e que conta com, aproximadamente, 180.000 habitantes

A população do estudo foi composta pela totalidade dos estudantes do Curso técnico de enfermagem, os quais já contam com a formação de auxiliar de enfermagem e trabalham nos serviços de saúde do município, num total de 20 estudantes. Participaram efetivamente do estudo 18 estudantes, os quais responderam a um questionário com perguntas abertas sobre as motivações e as desmotivações para trabalhar na área da saúde, além da caracterização sociodemográfica.

Os dados de caracterização foram apresentados de forma descritiva e obtidos a partir das perguntas abertas. Após a coleta, eles foram submetidos à técnica de análise de conteúdo, definida como "um conjunto de técnicas de análise das comunicações visando à obtenção, por meio de procedimentos sistemáticos e objetivos de descrição do conteúdo das mensagens, de indicadores que permitam inferência de conhecimentos relativos às condições de produção/ recepção destas mensagens". Entre as técnicas de análise de conteúdo, optou-se pela modalidade temática por ser mais adequada à investigação qualitativa( ${ }^{(9)}$.
Na utilização da técnica de análise de conteúdo, modalidade temática foram seguidas três etapas, compreendendo a pré-análise, em que foi realizada leitura atenta das narrativas dos entrevistados. Isso permitiu organizar o material, considerando os critérios de exaustividade, representatividade, homogeneidade e pertinência, a formulação de hipótese e os objetivos em relação ao material qualitativo, levando à definição das unidades de registro. Na segunda etapa, os dados foram codificados e organizados em núcleos de compreensão, denominados de categorias temáticas e, na sequência, feita a interpretação dos dados, tendo como base o quadro teórico referente aos aspectos oriundos das narrativas $^{(9)}$.

A coleta de dados foi realizada após a autorização do Comitê de Ética em Pesquisas com Seres Humanos da Faculdade de Medicina de Marília, sob o protocolo número 490/10. Após prestar esclarecimento sobre a finalidade do estudo, os estudantes que concordaram em participar assinaram o Termo de Consentimento Livre e Esclarecido. Na apresentação dos dados qualitativos, para garantir o sigilo, as narrativas receberam códigos numéricos, seguidos da idade dos participantes e da letra $\mathrm{F}$ para sexo feminino e $\mathrm{M}$, para o sexo masculino.

\section{RESULTADOS E DISCUSSÕES}

Entre os respondentes do questionário, 16 são do sexo feminino e dois do masculino. Embora nos últimos anos tenha ocorrido a migração dos trabalhadores masculinos para setores antes predominantemente femininos e aumento da participação feminina em posições antes limitadas aos homens, na força de trabalho em saúde de nível médio e elementar ainda predomina um número maior de mulheres $^{(1)}$. A justificativa de ser uma profissão eminentemente composta por mulheres pode estar relacionada ao fato de que elas sempre realizaram o cuidado e a educação dos filhos e, assim, o cuidado aos doentes também passou a ser parte do trabalho feminino, constituindo quase uma extensão do trabalho doméstico ${ }^{(10)}$.

Ressalta-se que, mesmo frente ao aumento da força de trabalho feminino no mercado de trabalho, muitas condições de desigualdades continuam existindo entre os sexos, como a assimetria de divisão do trabalho doméstico, reduzida distribuição do poder e desigualdades salariais ${ }^{(1)}$.

A respeito da idade dos componentes do grupo pesquisado, 10 estavam entre os 40 e 49 anos de idade, cinco alunos estavam entre os 20 e 29 anos, dois entre os 30 e 39 e apenas um com 50 ou mais anos. No que 
se refere ao local de trabalho, oito trabalhavam em unidades básicas de saúde tradicionais; sete em ambiente hospitalar, nas áreas de clinica médica e centro cirúrgico, enquanto três, no Programa Saúde da Família.

A respeito dos anos de experiência profissional na área da saúde, seis estudantes têm entre 10 e 19 de experiência; oito, entre 20 e 29, dois entre 30 e 39 e um aluno, acima de 40 anos.

A respeito da remuneração, a metade dos alunos não informou o valor de sua renda, enquanto a outra admitiu que gira entre um e três salários mínimos por mês. É preciso considerar, no entanto, que aqueles que manifestaram uma renda maior trabalham em dois empregos.

Ao se considerar a faixa etária e o tempo de serviço na atividade de enfermagem, associados ao salário, pode-se afirmar que, ao longo dos anos de trabalho, não tem havido valorização dessa experiência, possibilitando ascensão e crescimento profissional, o que é importante na manutenção do interesse e na motivação para o trabalho.

A manifestação da motivação para o trabalho na área da saúde pelos entrevistados possibilitou elencar as seguintes categorias temáticas: "O sentimento de realização e responsabilidade profissional"; "O incentivo externo, influenciando a manutenção da profissão". Em contrapartida, embora não fosse o objetivo da pesquisa, a análise das falas possibilitou também identificar fatores que desmotivam os profissionais, elencando-se as seguintes categorias. 0 que desmotiva esses profissionais refere-se à "falta de opção frente ao desejo de atingir novos patamares na profissão" e "desgaste pessoal diante do sofrimento alheio e do próprio".

\section{Sentimento de realização e responsabilidade profissional}

O homem, ao longo de sua vida, busca realizar o seu sonho, seja profissional, familiar ou afetivo. Passa, então, a estabelecer metas e identificar prioridades para alcançar o seu objetivo. Nesse sentido, foram encontradas algumas falas que se referem ao fato de trabalhar na enfermagem como uma realização profissional, ou seja, como um sonho que se concretizou.

(...) desde pequena eu brincava em ser enfermeira e que trabalhava em um grande hospital, famoso. Hoje observo que este sonho tem se concretizado em minha vida. $E 2,37$ anos, $F$
O desenvolvimento vocacional advém de um processo contínuo que, a partir das diversas experiências pessoais, escolares e profissionais, proporciona a emersão das potencialidades, dos interesses e das necessidades que permearão a conduta vocacional do indivíduo. Apesar de existirem alguns momentos cruciais, em que o indivíduo precisa fazer uma escolha profissional, como o vestibular ou um processo seletivo para obter emprego, é fundamental repensar essa escolha ao longo da vida, pois a satisfação profissional é extremamente importante ${ }^{(11)}$.

Considera-se que $o$ ato de trabalhar deve permitir ao trabalhador muito mais do que a simples possibilidade de sobrevivência, devendo abranger a realização, o crescimento e o reconhecimento profissional, o que resulta no aumento da capacidade de produção do indivíduo, incluindo sentimentos de participação e de responsabilidade no trabalho, despertando a criatividade do profissional(12).

Outro aspecto que chama a atenção é o fato de sentirem que a inserção profissional é mérito e fruto de muito esforço, embora desenvolvam carga horária extensa que se acresce à realização do curso.

(...) confesso que me sinto realizado profissionalmente, embora não seja fácil trabalhar muitas horas, manter-se atualizado em minha profissão, através de estudos e, sempre manter um sorriso nos lábios para os pacientes que eu assisto. E4,46 anos. $F$

(...) em plena epidemia da H1N1, senti como a minha profissão é de responsabilidade e vi o quão é necessário me manter atualizada sobre questões de medidas de higiene para que eu pudesse ajudar a população a se prevenir adequadamente desta doença. E15, 49 anos, $F$

Depreende-se dos depoimentos a existência de motivação para o trabalho, compreendida como um estado psicológico de disposição ou vontade de perseguir uma meta ou realizar uma tarefa, impulsionada por fatores internos. Esses fatores referem-se a necessidades, aptidões, interesses e habilidades do indivíduo, que o fazem capaz de realizar determinadas atividades e não outras, que o fazem sentir-se atraído por certas ações e evitar outras, que os fazem valorizar certos comportamentos e menosprezar outros. São os impulsos interiores, de natureza fisiológica e psicológica, afetados por fatores sociológicos, necessidades, frustrações, aptidões, habilidades, atitudes e interesses. Assim, o resultado do trabalho humano deve 
proporcionar sentido, trazer orgulho e prazer a quem o executa $^{(13)}$.

Frente a tais considerações, pode-se afirmar que os profissionais entrevistados, mesmo diante das situações adversas que levam ao sofrimento, conseguem visualizar a relevância do seu papel profissional, mantendo-se por anos a fio na profissão. Nessa trajetória, buscam elementos que fazem com que tenham sentimentos de realização frente à responsabilidade que representa o cuidado do outro, com apropriação dos avanços inerentes ao mundo globalizado.

\section{0 incentivo externo influenciando na manutenção da profissão}

Nas respostas dos participantes, identificam-se a realização e a satisfação com as atividades que exercem, por influência de fatores motivacionais externos. Segundo eles, os seus familiares tiveram significativo papel tanto para sua inserção, aprimoramento profissional e até mesmo para manterem-se no trabalho, pois relatam que, se não fosse o apoio deles, já teriam desistido de suas profissões, devido ao baixo valor salarial.

(...) muitas vezes pensei em desistir dessa minha profissão e tentar algo em que pudesse ser melhor remunerado, mas devido a incentivos de minha mãe $e$ dos meus irmãos que também trabalham na área de saúde, resolvi perseverar. E9, 29 anos, M

(...) quando eu optei pelo curso de auxiliar de enfermagem, eu acreditava que meus familiares iriam criticar a minha escolha. Hoje, já trabalho na área há mais de 10 anos, vejo que sou motivo de orgulho e fonte de renda para muitos deles. E6, 41 anos, $F$

A família é o primeiro grupo de participação e referencial, dada a sua enorme importância na vida de qualquer indivíduo. Ela transmite aos filhos seus valores e atitudes, tanto positivos quanto negativos, podendo exercer um papel importante na vida das pessoas e influenciar na escolha de determinada profissão ${ }^{(14)}$.

Além disso, observa-se que a identificação profissional pode ser influenciada pela história do indivíduo, pelas experiências na infância com a família, bem como pelas necessidades impostas pelo cotidiano, levando-o a refletir sobre a sua escolha profissional.

No que se refere aos fatores de motivação externa, referidos pelos entrevistados para manterem-se no trabalho, observa-se que estão relacionados aos laços familiares. Ao considerar que esses fatores compreendem os estímulos ou os incentivos que o ambiente oferece à pessoa, despertando sentimentos de interesse a respeito de recompensas a serem alcançadas $^{(14)}$, poder-se-ia esperar que houvesse recompensas do entorno ao seu processo de trabalho, como, por exemplo, o reconhecimento de gestores, de colegas ou dos próprios usuários.

O estudo permitiu, ainda, a identificação de fatores desmotivadores para o trabalho, conforme seguem.

\section{A falta de opção frente ao desejo de atingir novos patamares na profissão}

Constatou-se que os entrevistados também descrevem que foram levados ao exercício das atividades na área da saúde por ser a única opção que tiveram para ocupar um lugar no mercado de trabalho.

(...) quando era jovem, havia certa pressão por parte dos meus familiares para eu continuar estudando. Ir à faculdade seria impossível devido ao custo financeiro. Acabei optando por um curso técnico (auxiliar de enfermagem). E12, 39 anos, $M$

(...) o meu desejo em cursar a faculdade de enfermagem era intenso, mas devido à situação financeira dos meus pais eu não podia, portanto acabei escolhendo o curso de auxiliar de enfermagem, para que, com o salário que eu recebesse trabalhando na área, eu pudesse realizar o curso de enfermagem. E18, 47 anos, $F$

As falas acima reforçam a desigualdade social e o processo de exclusão das classes menos favorecidas. A desigualdade de oportunidades para o ingresso na universidade ou em escolas conceitualmente melhores apresenta-se muito antes do ensino superior, uma vez que as pessoas, em desvantagens sociais, muitas vezes não são adequadamente preparadas para o nível superior $^{(15)}$.

Assim, é possível que muitos talentos não estejam sendo devidamente aproveitados. Além disso, esse fato pode gerar desmotivação e frustração frente às atividades que desenvolvem. A este favor, o Plano Nacional de Educação para o decênio 2001-2010 expressa, para o final do período, o ingresso de $30 \%$ dos jovens entre 18 e 24 anos em cursos superiores ${ }^{(16)}$. Considerando a faixa etária dos entrevistados, compreende-se que tal política não contempla, a contento, seus ideais e projeções. 
Desgaste pessoal frente ao sofrimento do outro e ao próprio sofrimento

No que se refere à desmotivação, os participantes apontam a convivência com o sofrimento do outro e o seu próprio sofrimento. Muitas vezes, assistir ao sofrimento do doente e de seus familiares gera sentimento de impotência e frustração do profissional, principalmente frente às situações irreversíveis.

(...) muitas vezes meu sentimento é de impotência, pois com tantos anos de profissão (mais de 20), ainda não aprendi a lidar com a morte do doente a que eu prestei atendimento, seja em domicílio ou no hospital. E8, 53 anos, $F$

Entre as situações que fazem parte do cotidiano do trabalho da equipe de enfermagem está a necessidade de lidar com a dor, a doença, a morte e com a angústia e ansiedade de pacientes e familiares. $O$ sofrimento frente à morte demonstra que os profissionais não estão preparados para lidar com tal situação, pois geralmente não existe um apoio institucional para o seu enfrentamento $^{(17)}$.

Dessa forma, há necessidade de investimentos para a criação de espaços de diálogo, nos quais se possa refletir sobre o processo de trabalho desenvolvido, com a finalidade de compartilhar as angústias, as dores e as dificuldades, mas também os prazeres e com isso resgatar o respeito, o incentivo ao trabalho e a própria interação entre a equipe. É essa a perspectiva da educação permanente que agora, em forma de lei, constitui uma potente estratégia para viabilização desse cenário.

Além do desgaste ao vivenciar o sofrimento do outro, os participantes do estudo também manifestam sofrimento inerente às suas condições de trabalho, como a baixa remuneração e a necessidade de assumir dupla jornada de trabalho, considerando que, muitas vezes, são arrimos de família.

(...) trabalhar na área da saúde para mim se resume na oportunidade de melhorar o meu salário, tendo chance de trabalhar em dois empregos, durante o dia (UBS) e o outro, à noite (cuido de um idoso). Não quero isso para os meus filhos, me desgasto demais, quero que eles escolham outra área para trabalhar. 10,28 anos, $F$

(...) trabalho no período da manhã em um hospital e, no período da tarde, na unidade básica de saúde. Confesso que tenho me desgastado muito e que eu poderia ser mais dedicada à minha profissão se eu não precisasse da renda dos dois empregos juntos. E5,42 anos, $F$

O trabalho dos profissionais de enfermagem, especialmente os de nível médio, associa-se à baixa remuneração por se tratar de uma atividade que, ao longo dos anos, foi predominantemente manual. $\mathrm{Na}$ atualidade, o componente intelectual como força de trabalho tem a possibilidade de acumular mais valia aos trabalhos ${ }^{(18)}$.

O Brasil, ao contar com um grande contingente de trabalhadores de nível médio na área da saúde, acumulou uma dívida social e um passivo de trabalho precário, além de grandes diferenciais de remuneração inter-profissional ${ }^{(1)}$.

Este aspecto reflete diretamente nas condições de trabalho, uma vez que os profissionais acumulam mais de um emprego, levando-os ao desgaste e à redução na produtividade. Frente às características do trabalho em saúde que se pauta no trabalho vivo em ato, é possível que esta condição esteja interferindo nas relações cotidianas com os usuários e dificultando o acolhimento, o vinculo e a responsabilização por suas necessidades de saúde.

\section{CONSIDERAÇÕES FINAIS}

Devido à complexidade do trabalho em saúde, necessita-se de profissionais com perfil adequado para essa função e, para tal, torna-se fundamental compreender suas necessidades e investir em espaços de reflexão sobre o processo de trabalho.

Os participantes deste estudo referem que a motivação para as atividades que exercem está relacionada aos fatores internos, como o sentimento de responsabilidade profissional e aos externos ligados ao incentivo ou necessidades familiares. Por outro lado, também revelam que foram levados ao exercício da atividade por falta de outra possibilidade. Além disso, indicam condições desmotivadoras, como o sentimento de desgaste pessoal frente às vivências com o sofrimento do outro e com o próprio sofrimento, com destaque para a baixa remuneração cuja consequência se traduz na necessidade de exercer dupla jornada de trabalho.

Revela-se, assim, que esses profissionais convivem, lado a lado, tanto com o prazer como com o sofrimento no trabalho, parecendo possível considerar que eles obtêm um "saldo positivo" frente a tais vivências, ao se considerar que exercem a profissão já há alguns anos, acrescendo-se o interesse em realizar o curso de 
formação técnica, o que Ihes possibilita atualizar os conhecimentos, além de ascender na carreira profissional e se manter no mercado de trabalho. No entanto, não se pode subestimar o fato negativo quando apontam que exercem a profissão por falta de opção.

Frente a tais resultados, constata-se que ainda é preciso implantar políticas públicas com vistas a

\section{REFERÊNCIAS}

1. Machado $M H$, Wermelinger $M$, Tavares MFL, Moysés NMN, Teixeira M, Oliveira ES. Análise da força de trabalho no setor saúde no Brasil: focalizando a feminização [Internet]. Rio de Janeiro (RJ): Fundação Oswaldo Cruz - Fiocruz. Escola Nacional de Saúde Pública "Sergio Arouca"; 2006. [citado em: 20 maio 2010]. Disponível em:

http://www4.ensp.fiocruz.br/observarh/arquivos/FTSRELATORIO. pdf

2. Bassinello GAH, Bagnato MHS. Projeto Larga Escala: uma análise a partir da bibliografia existente. Esc Anna Nery Enferm 2009;13(1): 194-200.

3. Bonfim MIRM, coordenador. Formação docente em educação profissional técnica na área da saúde: a organização pedagógica do trabalho docente em saúde. Rio de Janeiro (RJ): Fiocruz; 2009.

4. Secretaria de Gestão Pública do Estado de São Paulo (SP). Programa de Formação de Profissionais de Nível Técnico na Área da Saúde no Estado de São Paulo - TECSAÚDE, Fundação do Desenvolvimento Administrativo - FUNDAP. Manual de monitoramento e supervisão do Curso Técnico de Nível Médio em Enfermagem: módulo de habilitação [Internet]. São Paulo (SP): Secretaria de Gestão Pública do Estado de São Paulo; 2009. [citado em: 20 maio 2010]. Disponível em:

http://tecsaude.sp.gov.br/pdf/manual_sup.pdf

5. Ministério da Educação (BR). Conselho Nacional de Educação. Resolução CNE/CEB no 04/99. Institui as Diretrizes Curriculares Nacionais para a Educação Profissional de Nível Técnico [Internet]. Brasília (DF): Ministério da Educação; 1999. [citado em: 20 maio 2010]. Disponível em: http://portal.mec.gov.br/setec/arquivos/pdf/RCNE_CEB04_99.pd f

6. Pereira MJB et al. A enfermagem no Brasil no contexto da força de trabalho em saúde: perfil e legislação. Rev Bras Enferm 2009;62(5):771-7.

7. Lima EC, Appolinário RS. A educação profissionalizante em enfermagem no Brasil: desafios e perspectivas. Rev Enferm UERJ 2011;19(2):311-6.

8. Bógus CM, Bersusa APS, Martins CL, Escuder MML. Conhecendo egressos do curso técnico de enfermagem do PROFAE. Rev Esc Enferm USP 2011;45(4):945-52.

9. Minayo MCS. O desafio do conhecimento: pesquisa qualitativa em saúde. 12a. ed. São Paulo (SP): Hucitec; 2010.

10. Pereira WR, Bellato R. O trabalho da enfermeira: uma abordagem sob perspectiva da teoria feminista. Texto \& Contexto Enferm 1995:4(1): 66-82.

11. Medina NVJ, Takahashi RT. A busca da graduação em enfermagem como opção dos técnicos e auxiliares de enfermagem. Rev Esc Enferm USP 2003:37(4): 101-8. 12. Melara SVG, Beccaria LM, Carta A, Contrin LM. Motivação da equipe de enfermagem em uma Unidade de Terapia Intensiva. Arq Cienc Saúde 2006;13(3): 128-35.

13. Nogueira LCM. Gerenciando pela qualidade total em saúde. 2a. ed. Belo Horizonte (MG): Editora de Desenvolvimento Gerencial; 1999.

14. Bohoslavsky R. Orientação vocacional: a estratégia clínica. 11a. ed. São Paulo (SP): Martins Fontes; 1998.

15. Reisberg L, Watson D. Igualdade e acesso no ensino superior. Rev Ensino Superior Unicamp [Internet]. 2010 nov [cited 2014 fev. 14];(2): 54-69. Available from: proporcionar maiores incentivos, tanto financeiros como os de formação para o profissional, uma vez que qualificação e a melhoria das condições de trabalho podem motivar o exercício da profissão e significar um maior avanço na implantação dos princípios e diretrizes do SUS.

http://www.gr.unicamp.br/ceav/revistaensinosuperior/ed02_nov embro2010/pdf/Ed02_novembro2010_igualdade-e-acesso.pdf. 16. Mota R. O acesso à universidade. Rev CE] [periódico na Internet] 2004 jul-set [citado em: 20 maio 2010];8(26):[3 páginas]. Disponível em:

http://www2.cjf.jus.br/ojs2/index.php/cej/article/view/620/800. 17. Dalmolin GL, Lunardi VL, Lunardi Filho WD. O sofrimento moral dos profissionais de enfermagem no exercício da profissão. Rev Enferm UERJ 2009;17(1): 35-40.

18. Antunes RLC. O caracol e sua concha: ensaios sobre a nova morfologia do trabalho. São Paulo (SP): Boitempo; 2005.

Artigo recebido em 26/10/2012.

Aprovado para publicação em 30/01/2014.

Artigo publicado em 30/06/2014. 